\title{
Eyes and Extraocular Photoreceptors in Midwater Cephalopods and Fishes: Their Roles in Detecting Downwelling Light for Counterillumination
}

\author{
R.E. Young ${ }^{1}$, C.F.E. Roper ${ }^{2}$ and J.F. Walters ${ }^{3}$ \\ ${ }_{1}$ Department of Oceanography, University of Hawaii at Manoa; Honolulu, Hawaii, USA \\ 2Department of Invertebrate Zoology, National Museum of Natural History, Smithsonian Institution; Washington, D.C., USA and \\ 3 Maui Community College; Hawaii, USA
}

\begin{abstract}
The means of detecting downwelling light for counterillumination in several midwater animals has been examined. Eyes and extraocular photoreceptors (dorsal photosensitive vesicles in the enoploteuthid squid Abraliopsis sp. B and pineal organs in the myctophid fish Myctophum spinosum) were alternately exposed to overhead light or covered by a small opaque shield above the animal and the bioluminescent response of the animal was monitored. Covering either the eyes or the extraocular photoreceptors resulted in a reduction in the intensity of counterillumination. Preliminary experiments examining the bioluminescent feedback mechanism for monitoring intensity of bioluminescence during counterillumination in the midwater squid Abralia trigonura indicated that the ventral photosensitive vesicles are responsible for bioluminescent feedback.
\end{abstract}

\section{Introduction}

Faint but highly directional daylight in midwaters of the open ocean silhouettes an opaque animal which could be visible, therefore, to predators below. Many animals, however, can use their own bioluminescence to eliminate their silhouettes. The idea that photophores are used for counterillumination (bioluminescent countershading) in midwater animals has been suggested, apparently independently, by a number of biologists (e.g. Dahlgren, 1916; Rauther, 1927; Jermanska, 1960; Fraser, 1962; Clarke, 1963); evidence for counterillumination from living midwater animals has accumulated rapidly in recent years. The radiance pattern of artificially induced luminescence in several midwater fishes (Denton et al., 1972) and shrimps (Herring, 1976) closely matched that of ambient sunlight. Midwater squid in an aquarium viewed from below by an observer became invisible when the squids' luminescence matched the overhead light intensity (Young and Roper, 1976). Cephalopods, fishes and shrimp in an aquarium regulated the intensity of their luminescence to match changes in the intensity of the overhead light (Case et al., 1977; Young and Roper, 1977). One squid varied the intensity of its luminescence over a range of about 16,000 -fold which corresponds to light changes that occur in clear oceanic waters over a depth range of nearly $300 \mathrm{~m}$ (Young et al., in preparation).

To counterilluminate properly, an animal must be able to determine the intensity of the downwelling light and must have some means to insure that its photophores respond appropriately. Young (1973) suggested that midwater squids utilize extraocular photoreceptors (dorsal photosensitive vesicles) to detect downwelling light. He also suggested that other extraocular photoreceptors (ventral photosensitive vesicles) detect light from the animal's own photophores, thereby providing a feedback mechanism for adjusting the intensity of the light from their photophores relative to the downwelling light.

Lawry (1974) suggested that the eyes of myctophid fishes detect downwelling light. Midwater fishes, however, have a prominent extraocular photoreceptor, the pineal organ, often lying beneath an unpigmented cutaneous window, which could be important in detecting downwelling light (McNulty and Nafpaktitis, 1976, 1977). In various midwater fishes, Nicol (1967), Young (1973), and Lawry (1974) suggested that photophores directed into 
the eyes provide feedback information to regulate luminescence.

The dorsal photosensitive vesicles in many midwater squids consist of a pair of organs located posterior to the eyes near the dorsal surface of the head (Fig. 1B). The paired ventral photosensitive vesicles are located near the ventral surface of the head, dorsal to the funnel. The funnel has numerous photophores directed at the ventral vesicles (see Young, 1973, 1978). The photoreceptive nature of these vesicles is well established (see review by Mauro, 1977).

The pineal organ in myctophid fishes lies in the dorsal midline of the head, between the eyes (Fig. 1B). Evidence that supports the photoreceptive nature of this organ has been reviewed by McNulty and Nafpaktitis (1977).

We now present behavioral data on the roles of the dorsal photosensitive vesicles and the eyes as detectors of downwelling light in squids, as well as the roles of the pineal organ and the eyes as detectors of downwelling light in myctophid fishes. We also present preliminary data on the role of the ventral photosensitive vesicles in squid as a photoreceptor for bioluminescent feedback of information for counterillumination.

\section{Materials and Methods}

Most data were collected during a cruise off leeward Oahu, Hawaii, aboard the University of Hawail's research vessel "Kana Keoki" in April, 1978. Preliminary data were accumulated during cruises in June and September, 1977.

Squids were captured in a shortened $3 \mathrm{~m}$ Isaacs-Kidd midwater trawl with a fine mesh liner (13 mm stretch mesh), a $505 \mu \mathrm{m}$ plankton net cod-end, and a conical cod-end bucket shielded against external light. Upon retrieval, the bucket was immediately wrapped in black plastic during the day or handled under red light at night to protect the animals' photoreceptors. Myctophid fishes were captured under a night-light with a dip net.

Living animals were placed in running seawater tanks in the totally dark aquarium-laboratory. Water temperatures were regulated to correspond approximateIy to temperatures normally encountered by these vertically migrating animals (about 70 to $9^{\circ} \mathrm{C}$ during the day and $15^{\circ}$ to $18^{\circ} \mathrm{C}$ during the night). Prior to experimentation, squid were maintained in aquaria in small, screened, plastic vials which allowed water circulation but restricted their movements to avoid injury. Fishes were placed in flexible tubes made from clear vinyl film through which water flowed continuously.

The squid studied were Abraliopsis spp. (2 undescribed species), Abralia trigonura Berry, 1913, Enoploteuthis sp. (undescribed species), and Pyroteuthis addolux Young, 1972. One species of fish was examined: the myctophid Myctophum spinosum (Steindachner).

The experimental apparatus (Fig. 1) was mounted in a box-like housing located on a vibration dampener. The specimen to be examined was placed in a tapered, transparent, flexible tube (clear vinyl film) with slowly flowing water. The taper provided a means of closely fitting the size of the tube to the size of the animal. A tube with an animal inside was placed on a clear acrylic platform that contained a small hole into which a fiber optic probe was inserted. Squid were positioned with the fiber optic probe beneath the photophore-covered head; fish were positioned with the probe beneath several photophores just posterior to the pectoral girdle. A $3.2 \mathrm{~mm}$ diameter fiber optic probe transmitted light from the animal's photophores to an EMI 9789 photomultiplier tube 1 , and light values were recorded on a Hewlett Packard 2-channel strip chart recorder. The light above the animals was provided by a $250 \mathrm{~W}$ slide projector located in the adjacent room. A diffuser placed in front of the projector bulb eliminated the image of the filament. Focused light from the projector passed through a series of neutral-density filters and an interference filter (transmission peak $=476 \mathrm{~nm}$, full width half maximum $=10 \mathrm{~nm}$ ), and was then deflected onto the animal by a $45^{\circ}$ mirror located about $20 \mathrm{~cm}$ above the specimen. The overhead light was thus a small source, with a gradually spreading beam located about $1.3 \mathrm{~m}$ from the animal.

The intensity of the overhead light was monitored via a $1.6 \mathrm{~mm}$ diameter fiber optic probe positioned beside the specimen and attached to an EMI 9789 photomultiplier tube; it was recorded in parallel on the same strip chart as the animal's luminescence. The intensity of overhead light was held at approximately $8.2 \times 10^{-4} \mu \mathrm{W} \mathrm{cm}^{-2}$. Previous work (Young et al., in preparation) demonstrated that this value is well within the range of light levels over which these animals can counterilluminate.

Opaque shields, made to size for each specimen, were used to shade the animal's photoreceptors from the overhead light.

\footnotetext{
Mention of a company name does not imply product endorsement.
} 

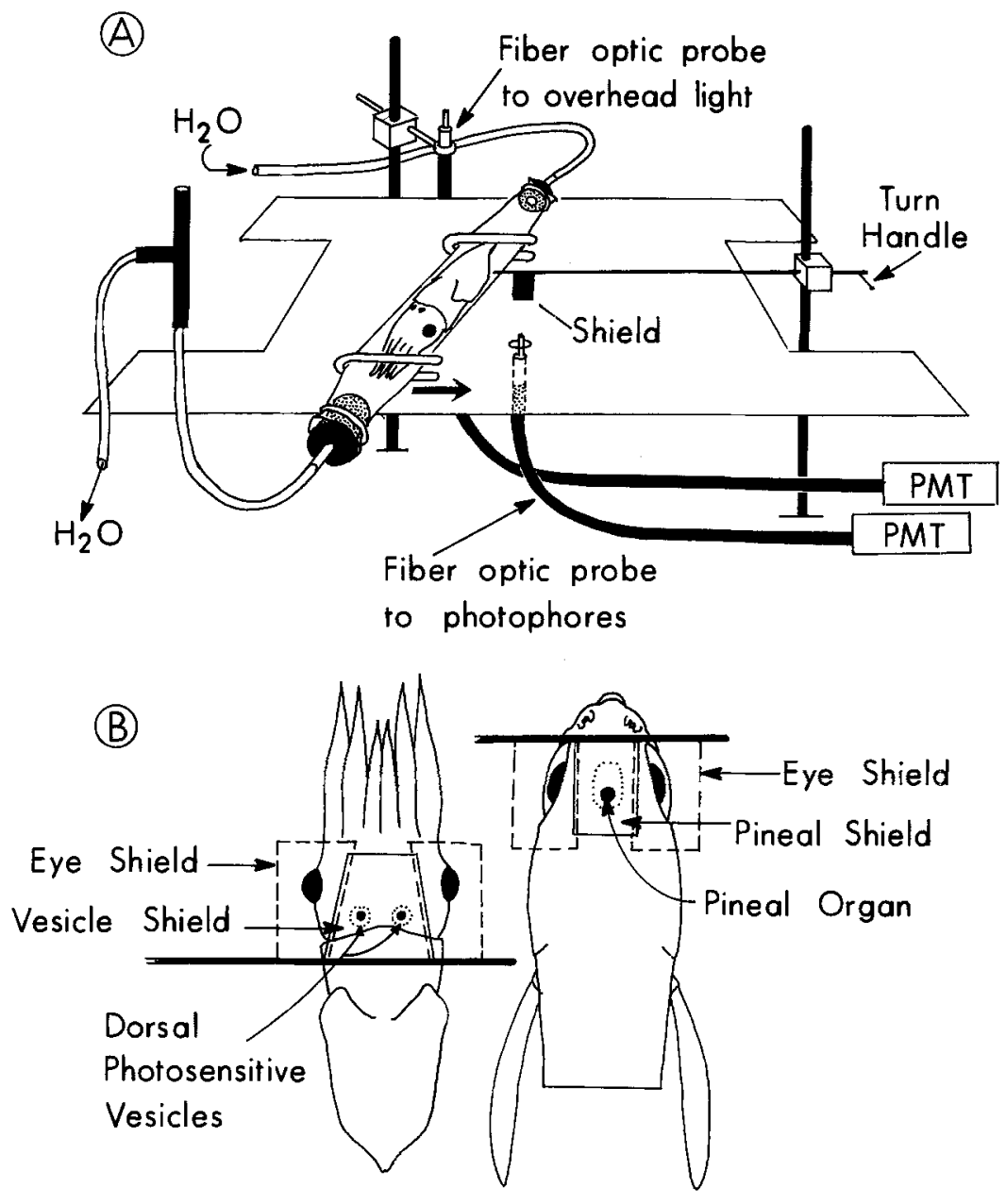

Fig. 1. (A) Experimental apparatus. Tube containing squid has been drawn to one side to show position of the fiber optic probe; PMT: photomultiplier tube. (B) Abraliopsis sp. B (left) and Myctophum spinosum (right). Outline drawings of the two species examined, showing approximate position of shields when covering photoreceptors

The shields consisted of heavy aluminum tape covered with black tape on one side and white tape on the other. The black tape prevented reflections from disturbing the animal during the lowering of the shield and the white surface aided the experimenter in correctly positioning the shield. The shields were attached to slender rods and could be rotated to a horizontal position dorsal to the organ being tested, thus cutting off the overhead illumination, or to a vertical position to allow light to enter the organs. The shields were positioned initially with the aid of dim red light.

Initial experiments were carried out with a broad overhead diffuser located immediately beneath the $45^{\circ}$ mirror. This system closely duplicates the radiance pattern of light in the ocean; however, the broad acceptance angle of the extraocular photoreceptors made shielding the eyes difficult without simultaneously interfering with light reception from the edges of the diffuser by these photoreceptors. As a result, this system was abandoned and replaced with the more directional lighting system described above.

To test the role of the eyes and extraocular photoreceptors in detecting overhead light, the animals were placed under the light regime and allowed to counteriliuminate; then one or the other organ was shielded and the animal's luminescent response recorded. Experiments on squids consisted of trials with (1) the dorsal vesicles covered, (2) the eyes covered, or, (3) both the eyes and dorsal vesicles covered. Each trial consisted of a $5 \mathrm{~min}$ exposure of the eyes and vesicles to overhead light, and the resulting luminescence gave the "initial value" against which later values were compared. This was followed by $5 \mathrm{~min}$ with one or both sets of organs covered 
with the opaque shield(s). At the end of each series of trials the overhead light was turned off for $5 \mathrm{~min}$. Since fishes exhibited a more rapid response, trials were reduced to 2 min with eyes and pineal organ exposed to overhead illumination followed by $2 \mathrm{~min}$ with one or both organs covered.

The animals were confined in the tubes, but they could not be completely immobilized. The luminescence of a totally immobilized squid becomes erratic, probably due to impairment of respiratory movements. A fish usually behaves similarly if its swimming movements are totally inhibited.

Animals in this confined system often required considerable time to adjust so that raising and lowering the shield, ship's vibrations, etc. did not disturb them. A disturbance is easily detected on the strip chart records as broadly fluctuating light intensities. Most specimens were tested over a period of about 6 to $12 \mathrm{~h}$ until the experiment was completed or until the animal's behavior became erratic.

While the light beam projected onto the experimental platform was highly directional, light received by the animal was less directional. The refraction of light at the curved sides of the tube in which the animal was located introduced some light to its eyes at oblique angles over a rather broad angular range. This oblique light was essential to the success of our experiments, since we discovered that squids, at least, can not detect exclusively vertical overhead light. We examined a squid in the following way. A small squid was positioned head-down in an aquarium, and the narrow beam from a high-intensity microscope lamp was directed at the dorsal surface of the animal. Light from the lamp hit the lens of the eye and was focused on the retina. The spot on the retina was bright enough to be seen through the pigment-covered eye and the head. When the light was centered over the dorsal surface of the head to simulate vertical light no image was formed on the retina. However, when the light was moved slightIy to one side but pointed at the squid, a distinct spot could be seen on the retina of the eye of that side. Measurements of the distances involved indicate that light will strike the retina on a horizontally oriented squid, if the light is at least $10^{\circ}$ to $12^{\circ}$ from the vertical. While we did not examine the fish in the same way, inspection suggests that they also may not be able to detect vertical light with their eyes. If eyes are used to help regulate counterillumination, their detection of oblique light that bears a constant ratio in intensity to the vertical component of the downwelling light apparently is sufficient.

We were able to conduct a few preliminary experiments on the feedback function of the ventral photosensitive vesicles of squid. The experimental procedure consisted of placing the squid in the vinyl tube under a constant source of diffuse overhead light to stimulate counterillumination. The ventral surface of the head and the ventral vesicles were illuminated via one branch of a fiber optic light probe located $2 \mathrm{~cm}$ from the ventral surface of the head. The ventral light passed through a wratten No. 45 blue filter (peak at $487 \mathrm{~nm}$ ) from a small light source regulated by a variable transformer. The other branch of the fiber optic probe passed from the same light source onto a photomultiplier tube. Light produced by the squid was detected by a separate photomultiplier tube via a separate fiber optic probe. The intensity of the ventral light was increased gradually until the squid responded by lowering its luminescence. In the range of response, several light intensities were examined. In each case the squid was given 5 min to adjust to the light values, at which time a reading was made. This system thus far has proven impossible to calibrate, since neither the percent of the ventral photosensitive vesicles illuminated, nor the loss of light prior to reaching the vesicles due to absorption by chromotophores and photophores on the funnel, could be determined.

\section{Results}

The data are presented as relative values. A counterilluminating animal can maintain a constant level of luminescence for long periods of time. If the animal is disturbed, however, this level may alter slightly. In addition, the animal may not always return to preciseIy the former level of luminescence when it recovers from a dark period. This inconsistency appears to be caused partly by the excitable condition of a confined animal and partly to slight movements the animal may make relative to the fiber optic probe. Movement of the animal over the probe slightly changes the position of the photophores "viewed" by the probe and may affect the recorded light value. For this reason, the data for any trial with an organ covered by a shield are presented as a percent of the initial level of luminescence when all photoreceptors were exposed at the be- 


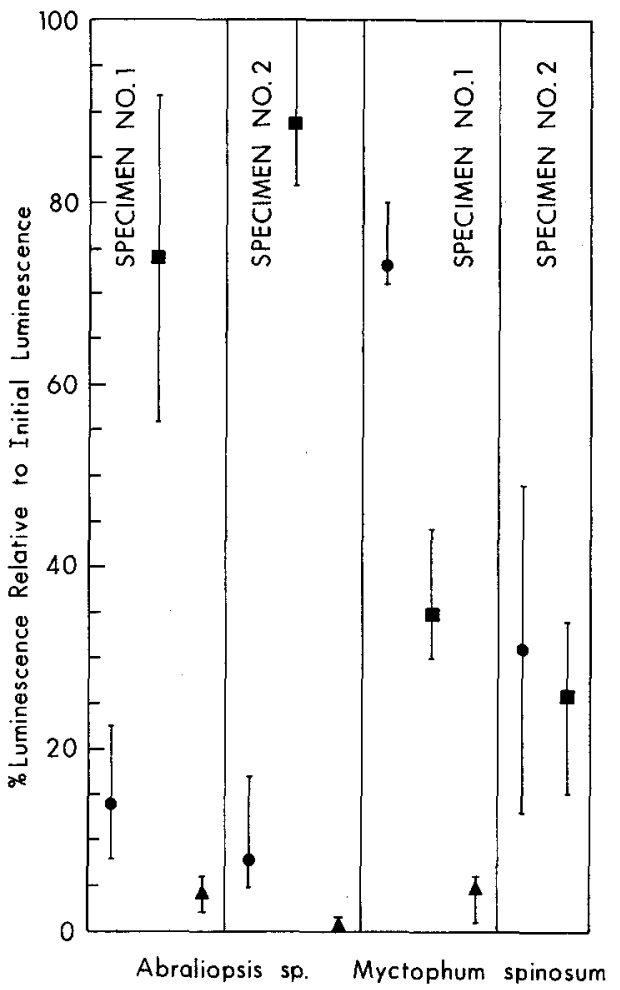

Fig. 2. Abraliopsis sp. B and Myctophum spinosum. Summary of test data indicating the extent of decrease in bioluminescence when photoreceptors are covered. Bars indicate range and symbols indicate means for a particular test. Circles: tests of extraocular photoreceptor(s); squares: tests of eyes; triangles: test of extraocular photoreceptor(s) and eyes. $n=4-10$

ginning of that trial. A summary of the data is presented in Fig. 2 .

\section{Abraliopsis sp. B}

This squid is undescribed. The designation B was adopted for this species by Young (1978). This short, stocky squid bears a dense array of small photophores on its ventral surfaces. Accounts of its counterilluminating abilities have been presented in earlier papers (Young and Roper, 1976, 1977). A transparent window above each dorsal photosensitive vesicle allows easy location of these organs and thus accurate positioning of the shield. During the day this species primarily occupies depths of 500 to $650 \mathrm{~m}$, and at night it occurs primarily in the upper $100 \mathrm{~m}$ (Young, 1978). Therefore, during both day and night the animal is exposed to light levels at which counterillumination could be of value.
Specimen No. 1

Male, $21 \mathrm{~mm}$ mantle length; captured at night; experiments began $4 \mathrm{~h}$ after capture and continued for another $12 \mathrm{~h}$. This squid was extremely irritable and frequently became erratic, forcing many trials to be aborted and restarted.

When only the dorsal photosensitive vesicles were covered by the opaque shield the squid decreased its luminescence to an average of $13 \%$ of its initial intensity when the vesicles were exposed. On the average, half of the decrease occurred in $18 \mathrm{sec}$. While the squid decreased its luminescence greatly with the vesicles covered, its decrease was even greater when both eyes and vesicles were covered. In these latter tests the squid's Iuminescence dropped to an average of $4 \%$ of its initial value, and half the decrease took place in about 5 sec.

When only the eyes were covered the squid's luminescence decreased to an average of 74 응 of its initial intensity. Half the total decrease in luminescence occurred in 3 to 6 sec. The variation in response was considerable and changed in a consistent manner: each successive trial gave a greater decrease than the previous one. This pattern is reflected in progressive increases in the intensity of luminescence during periods when no organs were covered. In several cases an initial drop in luminescence after the eyes were covered was followed by a gradual increase, resulting in the final recorded value being less than the maximum decrease.

Specimen No. 2

Female, $16.5 \mathrm{~mm}$ mantle length; captured during the evening. Experiments began $1 \mathrm{~h}$ after capture and continued for an additional $10 \mathrm{~h}$. This specimen was docile and not readily disturbed.

When only the dorsal photosensitive vesicles were covered, the squid's luminescence dropped to an average of $8.0 \%$ of its initial intensity when the vesicles were exposed (Fig. 3A). The luminescence dropped to half its final value in an average of about $16 \mathrm{sec}$. When both eyes and vesicles were covered the squid's luminescence dropped to an average of $0.6 \%$ of its intensity when both organs were exposed (Fig. 3C), and half of the decrease took place in about 5 sec.

When only the eyes were covered the squid's luminescence dropped to an average of $89 \%$ of its former level (Fig. 3B). Half of the decrease occurred in about 


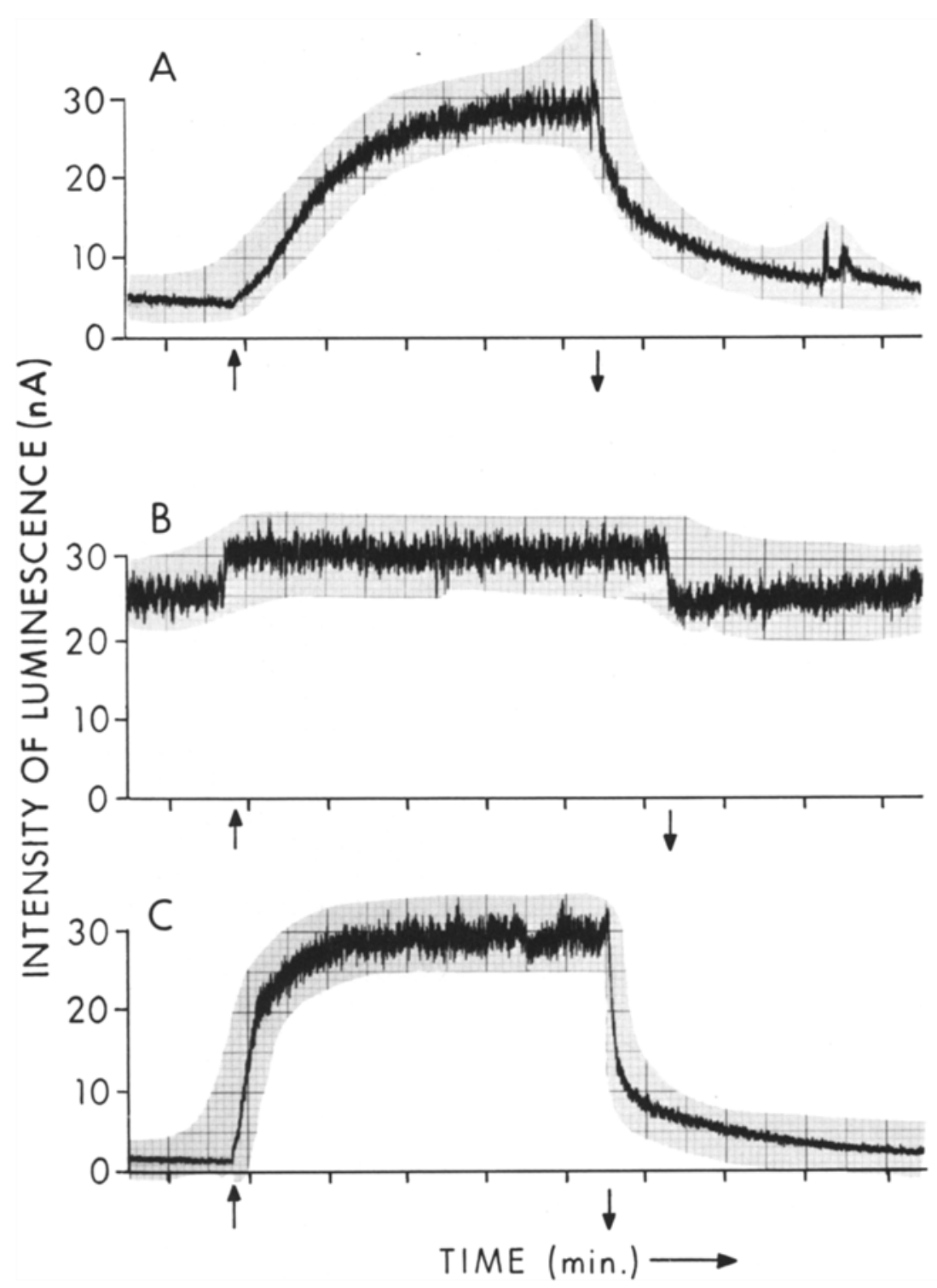

Fig. 3. Abraliopsis sp. B, specimen No. 2. (A) Test of dorsal photosensitive vesicles; (B) test of eyes; (C) test of both dorsal vesicles and eyes. Upward pointing arrows indicate shield covering photoreceptor raised, downward pointing arrows indicate shield lowered to cover photoreceptor

2 to $6 \mathrm{sec}$. In all trials the initial drop after the eyes were covered was greater than the final value recorded at the end of $5 \mathrm{~min}$. Indeed, in one trial the gradual increase following the initial drop resulted in a level of luminescence equal to that before the eyes were covered. If the magnitude of the initial drop is considered and not that at the 5-min point, the average decrease would be to $82 \%$.

\section{Myctophum spinosum}

The ventral surface of this fish is cov- ered with many large but rather broadly spaced photophores. The skin above the pineal organ lacks chromatophores, allowing easy location of the organ and accurate positioning of the shield. The organ lies over a heavily pigmented epithelium which provides a light shield from below. Clarke (1973) captured this species at $600 \mathrm{~m}$ during the day, but suggested that it may occur in shallower well lighted depths where it can detect and avoid the trawl. At night he captured it from $O$ to $15 \mathrm{~m}$, but again noted that it probably can avoid capture by the trawl. 


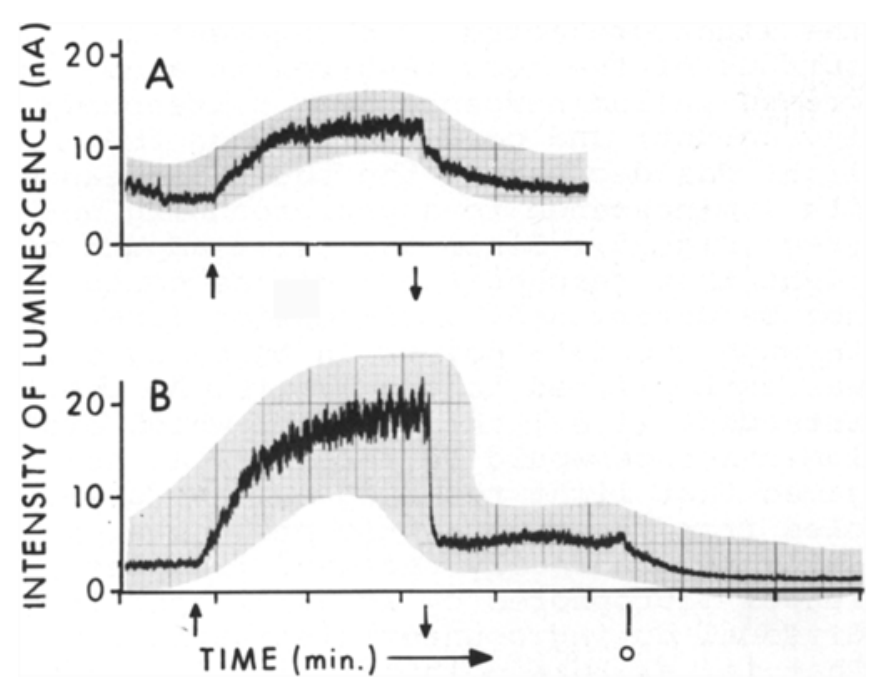

Fig. 4. Myctophum spinosum. Specimen No. 2. (A) Test of pineal organ; (B) test of eyes. Upward pointing arrows indicate shield covering photoreceptor raised; downward pointing arrows indicate shield lowered to cover photoreceptor. zero indicates overhead light turned off

Specimen No. 1

Male; $78 \mathrm{~mm}$ standard length; dip-netted at the night-light. Experiments began $3 \mathrm{~h}$ after capture and continued for an additional $6 \mathrm{~h}$. Myctophids placed in tubes with flowing water tended to move their heads from side to side as part of their swimming movements. In this specimen, movement was greatly restrained but not totally eliminated. Therefore, in placing shields over the head allowance had to be made for this movement, which resulted in shields being less than optimum size.

When the pineal organ was covered the Iuminescence dropped to an average of $73 \%$ of its former intensity when the organ was exposed. The range of values during trials was narrow (71 to 80\%). The drop in intensity was gradual: half the decrease occurred in 10 to $11 \mathrm{sec}$. When the overhead light was extinguished at the end of this series, which eliminated the visual response, a more rapid drop ensued. When the eyes were covered, the fish's luminescence dropped to an average of $35 \%$ of its former level. This drop in intensity was extremely rapid: half of the decrease occurred in about 1 sec. When the overhead light was extinguished at the end of this series, which eliminated the pineal response, a gradual drop ensued. When both eyes and pineal organ were covered the fish's Iuminescence dropped to an average of $5 \%$ of its former intensity when both photoreceptors were exposed.

Specimen No. 2

Female, $87 \mathrm{~mm}$ standard length; dipnetted at the night-light. Experiments began $3 \mathrm{~h}$ after capture and continued for an additional $5 \mathrm{~h}$. The head of this specimen was firmly wedged into the tube, eliminating all side movement. When the pineal organ was covered, the fish's Iuminescence decreased to an average of $31 \%$ of its initial intensity before the organ was covered (Fig. 4A). The decrease was gradual: half of the decrease occurred in an average of about 12 sec. The range of values during trials was broad ( 13 to $49 \%$ ). When the eyes were covered the fish's luminescence decreased to an average of $26 \%$ of its intensity prior to covering the eyes (Fig. 4B). The decrease was rapid: half of the total decrease took between 1 and 2 sec. Before tests could be run with both the eyes and the pineal organ covered, the fish's luminescence became erratic and all attempts to stabilize its behavior were unsuccessful. No further data were obtained.

\section{Comparisons between Sguid and Fish}

The responses of the squid and fish to covering the photoreceptors were somewhat different. The squid with dorsal photosensitive vesicles covered reduced its luminescence by about $90 \%$. With the eyes covered, however, it decreased its luminescence by only about 20\%. Myctophids reduced their luminescence with the pineal organ covered by an average of about $25 \%$ in one specimen and $70 \%$ in the other, while covering the eyes caused an average reduction of about $70 \%$ of the uncovered value. Therefore, covering the eyes in these fish elicited a response of greater magnitude than in these squid.

When the eyes of fish were covered, their luminescence reached half its total decrease in about 1 sec, while covering the pineal organ resulted in half the total decrease (which was usually less extensive) occurring in 10 to 12 sec. The differences with squid were not as dramatic and were less consistent. With the eyes covered, the squid's luminescence usually reached half its total decrease in 3 to $6 \mathrm{sec}$; however, the extent of the drop was small, about $20 \%$. With the vesicles covered, half the total decrease took 16 to $18 \mathrm{sec}$, but the drop was much more extensive, about $90 \%$. 


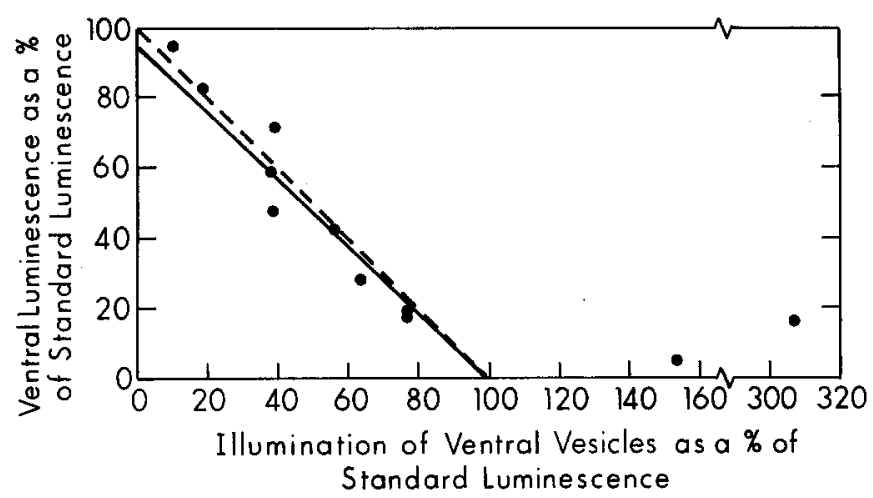

Fig. 5. Abralia trigonura. Effect on squid ventral luminescence of artificially illuminating the ventral photosensitive vesicles during counterillumination. Dashed line: predicted relationship; continuous line: regression line of data points excluding the two values on the far right (see text). Standard luminescence = ventral luminescence prior to experiment

However, when both the eyes and vesicles were covered, half the total decrease took place in about $5 \mathrm{sec}$. This indicates that in squid, as in fish, the response to the eyes being covered is faster than the response to the extraocular photoreceptors being covered.

\section{Abralia trigonura}

Female, $20 \mathrm{~mm}$ mantle length. Experiments began $1 \mathrm{~h}$ after capture during the day and continued for an additional $11 \mathrm{~h}$.

This squid generally occupies depths of 450 to $650 \mathrm{~m}$ during the day and occurs primarily in the upper $100 \mathrm{~m}$ at night (Young, 1978). It therefore occupies depths where counterillumination should be of value. This squid's ability to counterilluminate has been reported previously (Young and Roper, 1977). The feedback mechanism that involves the ventral photosensitive vesicles was examined in the present study.

Abralia trigonura has a large number of photophores on the dorsal surface of the funnel directed toward the ventral photosensitive vesicles and is, in this respect, similar to Abraliopsis sp. described by Young (1973). When light with sufficient intensity to interfere with the feedback mechanism was projected on the ventral vesicles, the squid responded by lowering its luminescence. six different light intensities within the range of response were projected onto the posteroventral surface of the head. Within this range, an increase in the light projected onto the ventral surface of the head resulted in a decrease in luminescence by a corresponding amount; and conversely, when the light was decreased, the squid increased its luminescence to a corresponding degree (Fig. 5). Since the exact amount of light that reached the vesicles could not be determined, a regression line through the data points in this region was extrapolated to the X-axis. At the intercept (i.e., the point at which bioluminescence would be zerol it was assumed that light received by the vesicles from the fiber optic probe was exactly that normally received from the funnel photophores by an unmolested individual during counterillumination. That is, at this point all the light for feedback is artificial, bioluminescence having decreased to the zero point as artificial light increased. A comparison of the slope of the regression line through the data points with the slope of a predicted line reveals little difference (Fig. 5). Fig. 5 also shows two data points that were not included in the regression calculation. These points represent light values approximately 1.5 and 3.0 times brighter than the projected "turn-off" point. At these values the squid's luminescence was not extinguished. Indeed, the greater illumination of the head at these two values resulted in brighter luminescence. Since the light was bright at this point and directed vertically upward, some light may have passed through the head to the dorsal vesicles, which complicated the squid's response.

\section{Discussion}

The data demonstrate that when an opaque shield is placed above the dorsal photosensitive vesicles of the squid or the pineal organ of the myctophid fish or above the eyes of the squid and fish when these animals are exposed to overhead illumination, the counterilluminating animals respond by decreasing their luminescence. Clearly, the animal's mechanism for detecting downwelling light was interfered with. Presumably the mechanism involves the organs shielded, although control experiments involving severing nerves to these organs were not performed.

Although we present data on detection of downwelling light for only two myctophids (Myctophum spinosum) and two squid (Abraliopsis sp. B), we obtained data on an additional 8 squids (Abralia trigonura, 5 individuals; Abraliopsis sp. A, 1 individual; Enoploteuthis sp., 1 individual; 
Pyroteuthis addolux, 1 individual). A large diffuse overhead light source was used with these individuals. While these data are less reliable than those obtained with the more directional illumination (see "Materials and Methods"), they are consistent with the data presented here.

The two myctophids gave quite different responses when the pineal organ was covered. The smaller individual, which was able to move its head slightly from side to side, may have received some light via the pineal organ during the tests; this would account for the lesser response, in this fish.

Apparently, both the eyes and extraocular photoreceptors in squids and fishes are involved in detecting downwelling light for counterillumination. These two organs are very different types of photoreceptors. The eyes are designed to detect images, while the extraocular photoreceptors presumably act as simple photometers. Neither organ by itself can give the animal all the information it requires for proper counterillumination.

As simple photoreceptors, extraocular organs presumably cannot distinguish between downwelling light and bioluminescent light; they simply record the total radiation falling on them. However, the midwater predator with image-forming eyes can detect "bright" Iuminescent spots and flashes against the fainter, uniform background of downwelling sunlight. The prey, therefore, must match only the intensity of the downwelling light if it is to be concealed by its Iuminescence. If the intensity of ambient bioluminescence approaches that of the downwelling light, a counterilluminating animal that relies only on extraocular photoreceptors would produce a ventral glow correspondingly brighter than the. downwelling light, making it vulnerable to detection. However, if this animal also relies on its own eyes to gauge the contribution of the ambient bioluminescence, it should get an accurate measure of the intensity of the downwelling light.

The eyes also have limitations as detectors of downwelling light. The laterally-directed eyes detect a strong vertical gradient in background illumination (downwelling light) across their visual field. In both squids and fishes the eyes have a slight forward tilt. Therefore, when an animal is tilted downward the maximum intensity within the visual field will be reduced compared with that of an animal in a horizontal position (upward tilting animals would further compound the problem). In addition, the eyes themselves are able to tilt slightly and, when tilted, to fix on a prey below the body axis, the animal's view of the downwelling light would be further reduced. The extraocular photoreceptors face vertically upward and, with their broad angle of acceptance, their "view" of downwelling light would be little affected by the animal's tilting. The dual mechanism involving eyes and extraocular photoreceptors, therefore, may allow these animals to separate downwelling light from bioluminescent light, while being unaffected by changes in body attitude or tilt of the eyes.

Our examination of the bioluminescent feedback mechanism for counterillumination in squid indicated that artificial illumination of the region of the ventral vesicles within a certain range of values reduced the squid's bioluminescence. Within this range, a given increase or decrease in artificial illumination resulted in a decrease or increase of corresponding magnitude in luminescence. These results suggest that the squid was attempting to maintain its luminescence at a constant level by relying on information received by the ventral vesicles and, therefore, that the ventral photosensitive vesicles of squid do indeed provide the bioluminescent feedback mechanism for controlling counterillumination.

Acknowledgements. We thank the officers and crew of the R.V. "Kana Keoki" and the numerous students of the University of Hawaii for their assistance aboard ship. We are especially grateful to $S$. Maynard who managed the trawling program and provided other logistic support. $B$. Nafpaktitis, K. Mangold, S. Maynard, F. Mencher and $\mathrm{J}$. Walsh reviewed the manuscript. This material is based on research supported by the National Science Foundation under Grant No. OCE76-81030 and the Smithsonian Institution. Hawail Institute of Geophysics Contribution No. 932.

\section{Literature Cited}

Case, J.F., J. Warner, A.T. Barnes and M. Lowenstine: Bioluminescence of lanternfish (Myctophidae) in response to changes in the light intensity. Nature, Lond. 265, 176-181 (1977)

clarke, W.D.: Function of bioluminescence in mesopelagic organisms. Nature, Lond. 198, $1244-1246$ (1963)

Clarke, T.: Some aspects of the ecology of lanternfishes (Myctophidae) in the Pacific Ocean near Hawaii. Fish Bull., U.S. 71, 401-434 (1973)

Dahlgren, U.: The production of light by animals. Light production in cephalopods. J. Franklin Inst. 81, 525-556 (1916) 
Denton, E.J., J.B. Gilpin-Brown and P.G. Wright: The angular distribution of the light produced by some mesopelagic fish in relation to their camouflage. Proc. R. Soc. (Ser. B) 182, 145-158 (1972)

Fraser, J.: Nature adrift. The story of marine plankton, $178 \mathrm{pp}$. London: Foulis \& Co. 1962

Herring, P.J.: Bioluminescence in decapod Crusta- cea. J. mar. biol. Ass. U.K. 56, 1029-1047 (1976)

Jermanska, A.: The structure and biological significance of light organs in the Teleostei. [In Polish] Przegl. zool. 4, 112-118 (1960)

Lawry, J.W., Jr.: Lanternfish compare downwelling light and bioluminescence. Nature, Lond. $247,155-157$ (1974)

Mauro, A.: Extra-ocular photoreceptors in cephalopods. In: The biology of cephalopods. Symp. zool. Soc. Lond. 38, 287-308 (1977)

McNulty, J.A. and B.G. Nafpaktitis: The structure and development of the pineal complex in the lanternfish Triphoturus mexicanus (family Myctophidae). J. Morph. 150, 579-605 (1976)

- Morphology of the pineal complex in seven species of lanternfishes (Pisces: Myctophidae). Am. J. Anat. 150, 509-530 (1977)
Nicol, J.A.C.: The luminescence of fishes. Symp. zool. Soc. Iond. 19, 27-56 (1967)

Rauther, M.: Echte Fische. Bronn's KI. Ordn. Tierreichs 6, 125-167 (1927)

Young, R.E.: Information feedback from photophores and ventral countershading in midwater squid. Pacif. Sci. 27, 1-7 (1973)

- Ventral distribution and photosensitive vesicles of pelagic cephalopods from Hawaiian waters. Fish. Bull. U.S. 76, 583-615 (1978)

- and C.F.E. Roper: Bioluminescent countershading in midwater animals: evidence in living squid. Science, N.Y. 191, 1046-1048 (1976)

- Intensity regulation of bioluminescence during countershading in living midwater animals. Fish. Bull. U.S. 75, 239-252 (1977)

Dr. Richard Edward Young Department of Oceanography 2525 Correa Road University of Hawaii at Manoa Honolulu, Hawaii 96822 USA

Date of final manuscript acceptance: December 15, 1978. Communicated by N.D. Holland, La Jolla 